\title{
SELECTED ASPECTS OF THE ROAD TRAFFIC SAFETY MANAGEMENT SYSTEM
}

\author{
Monika Stoma ${ }^{1}$, Jacek Caban², Agnieszka Dudziak ${ }^{1, *}$, Andrzej Kuranc ${ }^{1}$ \\ ${ }^{1}$ Department of Power Engineering and Transportation, Faculty of Production Engineering, University of Life Sciences \\ in Lublin, Lublin, Poland \\ ${ }^{2}$ Department of Automation, Faculty of Mechanical Engineering, Lublin University of Technology, Lublin, Poland \\ *E-mail of corresponding author: agnieszka.dudziak@up.lublin.pl
}

\section{Resume}

The article is an attempt to present the two modern concepts of safety management systems. The first is the sunflower pyramid used especially in Europe, the second is the ISO 39001 standard (Road Safety Management System) of international scope. The idea and possibilities offered by use of both concepts of safety management, as well as an attempt to assess the impact of their actions on decrease in fatalities in selected EU countries, were presented. As a result of the conducted analyses, a downward trend was noted as to the number of certificates issued for compliance with the ISO 39001 standard in the world, which may indicate an appearance of the more adequate management systems, or other tools or concepts to improve the road safety, or inadequate education society and low level of awareness in this area of stakeholders, including politicians, scientists, producers, drivers (professional and reliable), as well as other road users, including unprotected ones.

Available online: https://doi.org/10.26552/com.C.2021.2.F33-F42

\section{Article info}

Received 17 September 2020

Accepted 21 October 2020

Online 12 March 2021

\section{Keywords:}

city logistics,

traffic safety,

standardisation,

road situation

ISSN 1335-4205 (print version)

ISSN 2585-7878 (online version)

\section{Introduction}

Transportation of goods and people is a fundamental concern of modern societies [1]. The transport sector is influenced by a wide range of external social and economic factors, such as demographics, living standards of the population, urban planning, organization of production, structural changes in society and accessibility to transport infrastructure [2]. One of the trends of the last decade is a significant increase in road traffic [3]. As a result, the problem of the road traffic safety is now an important and often even a key issue in many countries. This is due to a large number of traffic incidents, especially those resulting in serious injuries or deaths of their participants. Since the road traffic safety is a growing concern for societies and governments around the world, more emphasis should be placed on improving infrastructure, vehicle condition and professionalism through training of drivers in the road transport sector. A necessary condition for reducing the number of road traffic accidents is also increasing knowledge of their main causes, as well as awareness of the road traffic safety of all interested parties, including politicians, scientists, manufacturers, machines operators, professional drivers, individual drivers and other road users.

\section{Literature review}

Road traffic accidents are a serious social problem in modern societies. Every year, about 1.35 million people die on the roads and about 50 million are injured [4-6]. It should be added that the so-called Unprotected Road Users (URU), i.e. pedestrians, cyclists and users of the two-wheel motor vehicles, by the European Union statistics, have a share in the road fatal accidents, which in 2014 was: $22 \%$ for pedestrians, $8 \%$ for cyclists and $18 \%$ for users of two-wheeled motor vehicles. Thus, unprotected road users make up $48 \%$ of all the fatalities and about two-thirds of all road traffic accidents victims [7]. The situation is similar in relation to other countries in the world - according to the WHO report for 2017, more than half of fatalities are pedestrians, cyclists and motorcyclists [6]. Most pedestrians are killed in Africa (40\%) and in the Middle East (34 \%). In Poland, this ratio is $29 \%$ (it was also at a similar level in Egypt, Estonia, Israel, Slovakia, Cyprus and Sudan). In contrast, for motorcyclists, the worst situation is in Southeast Asia (43\% killed) and in the western Pacific (36 $\%)$. The average for all of Europe is $11 \%$, this indicator is also at the same level in Poland.

Injuries in the road traffic accidents are the eighth leading cause of death in the world [8], more people die 


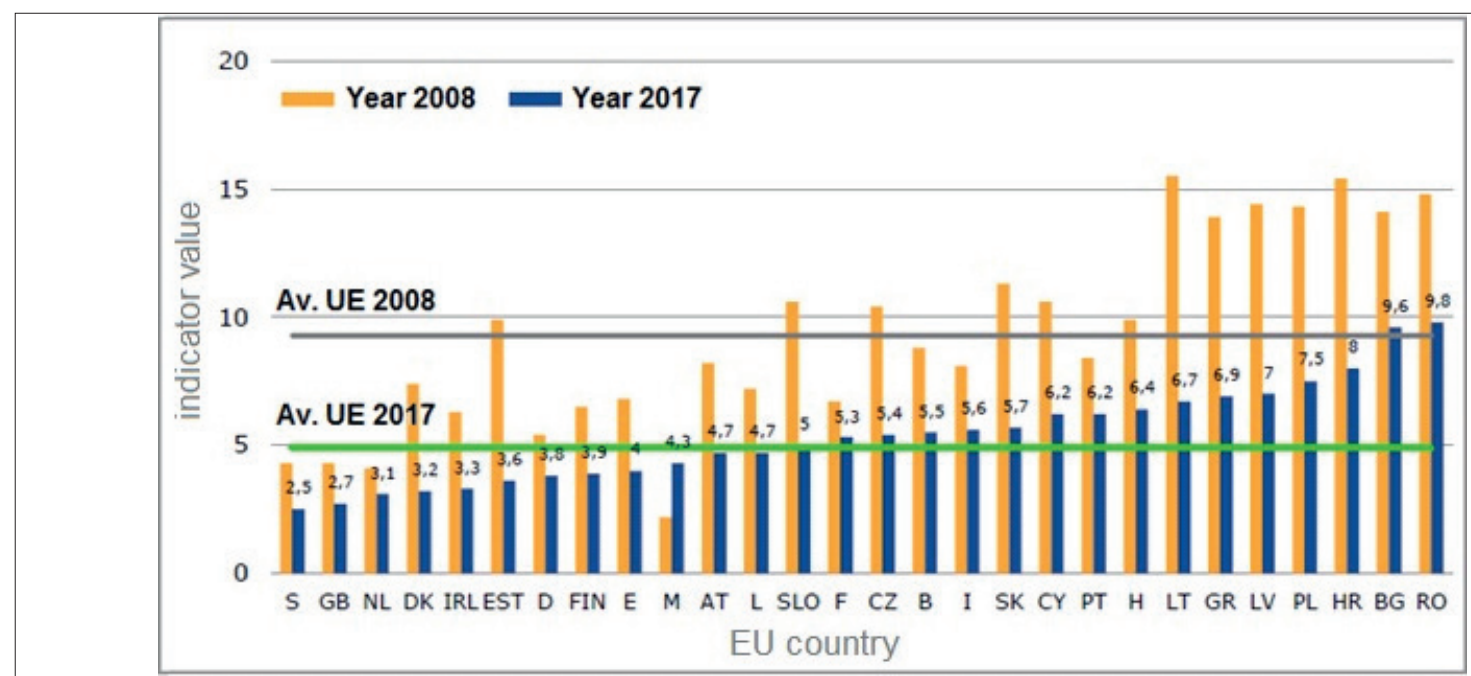

Figure 1 Demographic indicator: number of people killed/100,000 residents in EU countries in 2008 and 2017, prepared based on data provided by the European Commission [10]

on the road than die of AIDS or tuberculosis. It should be added that, according to WHO data, more than half of the people killed in the road traffic accidents are young people, aged from 15 to 44 years. Even worse, these statistics fall for people in the 10-24 age bracket, where the road traffic accidents kill more people than any other cause and according to WHO forecasts - it is expected that by 2030 this value will increase by $65 \%$. Especially in the low- and middle-income countries, the percentage of road traffic accidents is twice as high as in the high-income countries and is still rising. This is mainly due to the rapid increase in the automotive index in developing countries, without investments related to the road traffic safety at the same time. Current trends suggest that, unless an action is taken, the road traffic accidents will become the fifth most common cause of death by 2030, compared to e.g. tuberculosis (26th place) or malaria ( $15^{\text {th }}$ place). It should be added that differences between the high- and low-income countries will constantly increase [6]. It is also estimated that death as a result of road traffic accidents will become the second cause of health losses for men in 2030 and the main cause for children (age 5-14) from 2015 [9]. Such a scenario can be realistic if no new initiatives are taken to improve the state of the road traffic safety. Figure 1 presents a comparison of the demographic indicator: number of killed/100,000 residents in EU countries in 2008 and 2017.

The smallest value of this indicator in 2017 was in Sweden - 2.5 (in addition, the member countries with the best results in terms of the road safety were also the United Kingdom and the Netherlands), the highest in Romania 9.8 (a high rate can also be seen in Bulgaria and Croatia). In Poland the value of this indicator was 7.5. It should be added that European roads are among the safest in the world [11].

Other data and statistics contained in the WHO Report on fatalities in the road traffic accidents in the European Union in 2017 are also worrying. It follows from them that:

- $\quad 8 \%$ of traffic fatalities occurred on motorways, $55 \%$ on rural roads and $37 \%$ in urban areas.
- $\quad 76 \%$ of traffic fatalities on EU roads are men and $24 \%$ are women.

- almost $14 \%$ of road traffic fatalities are young people, aged from 18 to 24 years, while only $8 \%$ of the European population belongs to this age group.

- the proportion of elderly fatalities increased from $22 \%$ in 2010 to $27 \%$ in 2017 , because of demographic trends manifested around the world today (aging population).

It is worth noting that, as can be seen from the data presented in Figure 1, Poland has a permanently high rate of people killed in road traffic accidents. It should be added that in 2018 there were 31,674 road traffic accidents, as a result of which 2,862 people were killed and 37,359 people were injured [12]. In the same year, 436,414 road traffic collisions were reported to Police units. It is worth adding that in 2008 it was 5,437 traffic fatalities.

The consequences of collisions and road traffic accidents can be considered in both health and financial aspects. They represent a burden on individuals and society; they are important for various social groups and institutions: for people who participate in road traffic, for units directly involved in the road traffic safety (e.g. road rescue units) and for the whole society. For example, Kucmin et al. in [13], presented a study on the symptoms of post-traumatic stress disorder of paramedics caused by work in road traffic accidents. Social and psychological effects related to the road traffic safety are widely presented in monograph [14]. In [15], Hanzl also presents research on traffic management and control and possible costs related to its organization, caused by a road traffic accident and temporary traffic closure on the highway. The change in the organization of road traffic also affects the level of traffic safety in this area, because it increases the movement of trucks and passenger cars, causes communication difficulties in the local community. In turn, Drozdziel and Wrona [16] studied the issues of vehicles traveling on expressways and motorways in Poland. They indicated the legal conditions that regulate the rules for vehicles traveling on this type of 
roads and presented selected road incidents with serious consequences.

It should be added that it is expected that the share of the road traffic accidents, including fatal accidents, especially in relation to URUs may increase, despite development of information technologies, mainly due to the aging of the population, as well as the intensification of urbanization. Some of them can be prevented with relatively simple measures, while others require much more investment, especially in the areas of infrastructure, legislation and law enforcement [8].

Therefore, the new procedural solutions should be sought that would allow reducing the negative impact of the road traffic on society, the environment and economy. Improving global road safety is due to the broader vision of sustainable development and poverty reduction. Therefore, there was a need to create optimized road traffic safety management systems, under the basic assumption that effective organization of the road traffic safety management is one of the conditions for better results in this area [17-18]. Johnston [19] argues that key success factors in countries with the lowest mortality rates or greatest progress are due to the proper identification of problems and development, evidence-based strategies, combined with ambitious quantitative goals and transparent institutional accountability. The road traffic safety management contains all these elements.

Therefore, there is a need to create optimized concepts and the road traffic safety management systems. This is a challenge from the point of view of social benefits, but also political and economic [20]. It should be remembered, however, that to achieve a significant improvement in the road traffic safety at the national level, a systematic approach to the traffic safety management with precisely defined obligations and responsibilities is necessary. As shown by experience of some countries, this is not so obvious, because in many cases the undertaken actions are unsystematic, fragmented and not based on knowledge, which causes their ineffectiveness [21]. Bliss and Breen [22] suggest that effective of the road traffic safety management can be achieved through a variety of structural and procedural forms, making it difficult to identify one: good practice" model. Papadimitriou and Yannis [23] conducted comprehensive research on the road traffic safety management systems in 14 European countries, which showed that not all the elements of a "good practice" of the road traffic safety management are always met in all the countries, especially in those in worse condition economic.

\section{Objective of the work}

Therefore, the aim of this work is to present opportunities to improve the road traffic safety by implementing the concept of the road traffic safety management systems. As already mentioned, one of the solutions is the sunflower pyramid used in European Union countries. The second option is management according to the international ISO 39001 standard. The article is therefore an attempt to present the possibilities of both systems (concepts) in reducing the number of traffic fatalities in selected countries of the European Union and their relation to the demographic indicator (number of people killed/100,000 residents).

\section{Methodology}

In this study the possibilities offered by use of two concepts of the safety management are presented, as well as an attempt to assess the impact of their actions on the decrease in fatalities in selected EU countries.

Among the many standards and procedures functioning in relation to the RTSMS and allowing for benchmarking of the road traffic safety and safety trends and for a quantitative representation of national security, there is the so-called "SUNflower pyramid". It is intended to be used for security comparisons between all the countries in the European Union, as well as other countries around the world. This approach creates a conceptual framework to identify factors that improve the road traffic safety.

The second option is management according to the international ISO 39001 standard Road Traffic Safety Management System (RTSMS). This standard has been designed in such a way as to help organizations in implementing best practices, achieving compliance and meeting the requirements of partners and participants, while minimizing impact on the community and environment.

\section{$5 \quad$ Road traffic safety management}

The road traffic safety management is defined in accordance with the OECD road safety report as "a systematic process to reduce the number and severity of road traffic accidents" [24]. Studies and experience of many countries have shown that a significant reduction in the serious consequences of long-term road traffic accidents can be achieved by adopting a holistic road traffic safety system. This approach combines analysis of all the aspects of the road transport system that contribute to traffic accidents. Decisive here is the recognition that there are limits to human action that affect how people behave in traffic [25].

Improving the functioning of the road safety should therefore be considered in the context of the overall road traffic safety management system. This system can be described as "complex institutional structures involving cooperation and interaction involving the authorities that support the tasks and processes necessary to prevent and reduce the road traffic accidents" [26]. The road traffic safety management should be seen as a "production process" consisting of three interrelated components: institutional management functions create interventions that give concrete results [9]. 
For years, scientists have been trying to analyze the road traffic safety management systems in various countries and to assess the impact of the road traffic safety management elements on the effects in this area. Wong and Sze [27] conducted research to determine the impact of setting quantitative goals on reducing mortality for 7 European countries and found a significant positive impact. In turn, Broughton and Knowles [28] tried to estimate the expected reduction in deaths as a result of the implementation of the national the road traffic safety program in Great Britain. Chapelon and Lassarre [29] analyzed the structures, processes, data and methods used in the road traffic safety management system in France, with particular emphasis on showing how specific performance indicators are monitored to assess the progress of specific road traffic safety problems. Schulze and Kossmann [30] described the road traffic safety management tools implemented in Germany in order to explain the reasons for the safety deficit, define and recommend measures based on test results, assess the safety impact of one measure and constantly monitor to what extent the objectives of the national action plan for the road traffic safety are met.

Literature analysis allows one to state that the road traffic safety management systems are composed of many different components (structures, plans, processes, products, results, tools etc.), which makes it extremely difficult to describe them in a standard way. Moreover, despite the common belief that the better management structures and processes of the road traffic safety are associated with better effects of the road traffic safety, it turns out that this relationship is more complex and needs to be considered for specific cases. In fact, the relationship between the road traffic safety management system in the country as a whole and results of the road traffic safety in terms of road traffic fatalities has not been properly investigated [23].

\section{SUNflower approach}

\subsection{The genesis of the SUNflower approach}

Road traffic safety is often defined in terms of mortality: the number of fatalities in a given population. Mortality rates are primarily used to illustrate the rank of the road traffic safety or other traffic hazards in relation to mortality due to illness, work accidents or accidents at home. Such indicators and comparisons have the disadvantage that the degree of motorization is not taken into account here. Hence, another indicator is commonly used as a road traffic safety criterion, namely the mortality rate, defined as the number of fatalities per kilometre in the automotive sector. For those countries where such data are not available, the mortality rate is in turn defined as the number of fatalities per motor vehicle [31].

In order to solve problems in comparisons between countries in the field of the road traffic safety, the SUNflower model was developed, under which a target road traffic safety hierarchy was created. The name "SUNflower" comes from the abbreviation of a series of preliminary projects that concerned research on the state of the road traffic safety in Sweden, Great Britain and the Netherlands (the first letters of the names of countries: Sweden, United Kingdom, Netherlands), considered the three safest countries in the world [32]. The main research questions posed were: how have these countries become relatively safe countries over the years, what exactly has improved their road traffic safety, how can these countries learn from each other and what are the options for moving these aspects to other countries [33].

Later it was extended to six other European countries, in which three groups of three countries (SUN, Southern, Central) compared using the same methodology and the approach was given the name "Sunflower +6 ", [34]. It also allowed an additional translation of the methodology name, because the six countries that the study was extended to include traditional sun countries: three countries in the south of Europe: Greece, Portugal, Spain (with a particular focus on Catalonia) and three in Central Europe: the Czech Republic, Hungary and Poland. Third and latest research, conducted by Wegman and the team [35], they were referred to as SUNflowerNext. They created the framework for a comparative analysis of the state of security of countries and made the first attempt to capture this process in the index of security performance.

\subsection{The essence and elements of the SUNflower pyramid}

The SUNflower approach requires an understanding of the road traffic safety processes at various levels in the hierarchy of causes and effects, which in turn leads to road traffic accidents and costs for society. The main reference point is the model that describes the hierarchy of the road traffic safety objectives from "structure and culture" to "social costs" [32], as shown in Figure 2.

As it results from Figure 2, the "SUNflower" pyramid describes the road traffic safety management system in the context of a five-level hierarchy: (1) structure and culture, (2) safety measures and programs, (3) indirect effects safety performance indicators, (4) final results - number of fatalities and injuries and (5) social costs. Therefore, its basis is the structure and culture of a given country, but no less important are social trends such as aging of the society or urbanization.

The first, lowest layer consists of two main elements. The "structure" component refers to two dimensions: physical and operational (functional) structure, while the "culture" component focuses on how society and its citizens perceive the problem of the road traffic safety compared to e.g. the role of road traffic in society and its impact on the one hand on economic growth and prosperity and on the other - environmental effects. The term "security culture" is also used here. This layer describes the policy context, such as the public's attitude to risk and security, the organization 


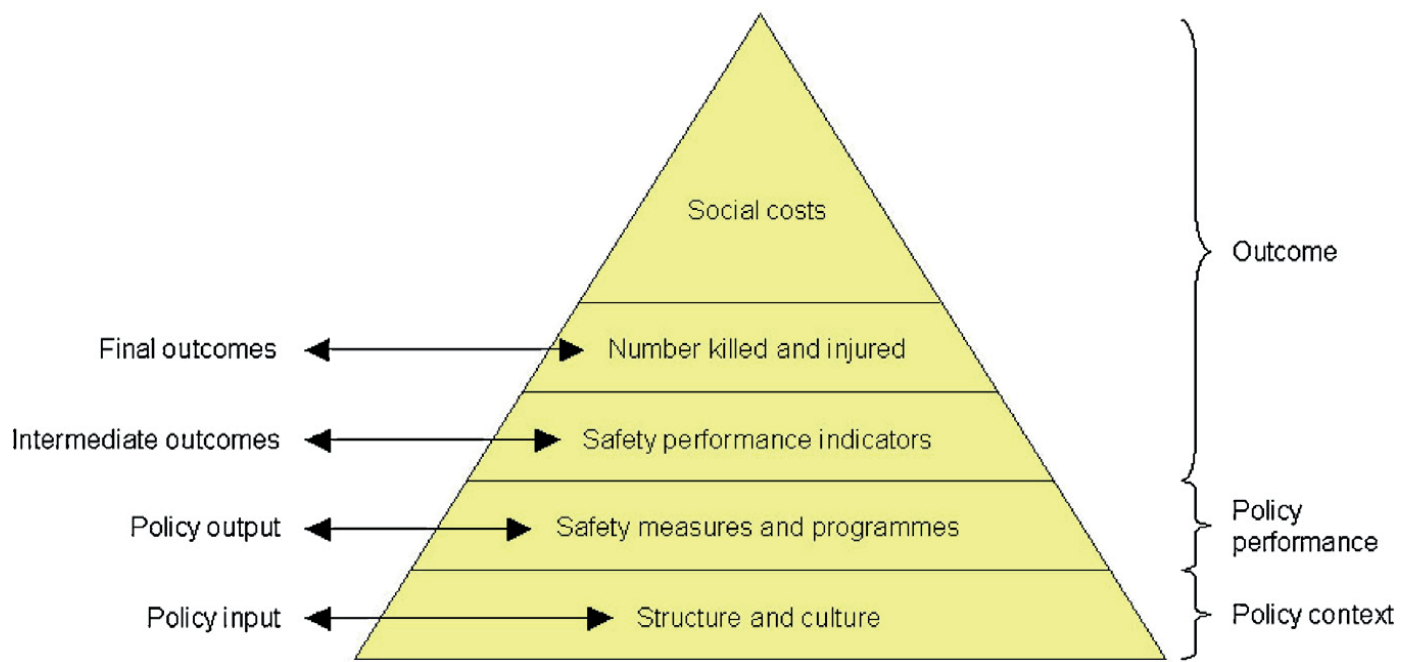

Figure 2 The hierarchy of the objectives of the road traffic safety, [32]

of the country, its history and culture. It follows that the level of the road traffic safety refers to the country's structural features and cultural (i.e. Policy "at the input"). The first level is closely related to the second, i.e. security measures and programs - "exit policy" - resulting from structural and cultural characteristics. This level reflects the effectiveness of the policy. Implementation of the policy concerns the quality of the road traffic safety strategy and the quality of its implementation. So it is a combination of how well the strategy was designed and how well the strategy-based action plans were implemented [36].

The next level is an intermediate layer that allows one to combine the first two layers with the real effects of road traffic accidents. It defines the operational level of the road traffic safety in the country and includes indicators for the road traffic safety regarding excessive speed, drunk driving, or the road network and the main features of vehicles. Level 4 provides information on the final results expressed in the number of road traffic accident victims; consists of different types of road risk indicators. They are necessary to understand the scale of the problem. The top of the pyramid (level 5) provides an estimate of the total economic and social costs of road traffic accidents [23].

To understand the state of the road traffic safety in a given country, one can move in the pyramid in both directions: from the bottom to top or from the top to bottom. For example, from a sociological point of view, one can first describe social attitudes towards drinking or excessive speed (the lowest layer "structure and culture"), then move up the pyramid to identify measures (such as legal restrictions and their enforcement) and thereby understand the extent of the offense and the associated losses and costs. On the other hand, from the point of view of the cost-effectiveness, the opposite direction can be taken by identifying which problems are associated with the highest costs and then tracking these problems to their origins and solving them in a cost-effective way. It should also be added that it is not necessary to start the analysis only from the lower or upper level, for example when monitoring the effects of established security measures.
Furthermore, some mechanisms are not related to the pyramid level sequence, e.g. a change in the number of unfortunate accidents as a result of government actions (the so-called publicity) can directly affect social attitudes [31].

\subsection{Road traffic safety indicators and the SUNflower pyramid}

The road traffic safety indicators relate to the operational level of the road traffic safety, which is affected by both the structural and cultural characteristics of a given country and the road traffic safety policy and thus are often referred to as "indirect effects" [23]. The purpose of their use is to try to fill the gap in the lack of knowledge about the causal relationship between the actions taken and the final results [37].

The road traffic safety indicators have three main functions: simplification, quantification and communication [38]. Basically, they are used to capture complex phenomena in a relatively simple way and therefore there is a risk of losing important information or observations. Nevertheless, according to Adriaanse, indicators usually use simplifications so that the complex phenomena can be quantified in such a way that communication is either enabled or stimulated. In addition, these indicators can be used for comparison between countries, their ranking and benchmarking.

Safety indicators are a kind of intermediate step in determining the impact of road traffic safety [31, 34]. They reflect those operating conditions of the road traffic system that affect the level of system security. The objectives of the indicators are [36]:

1. taking into account the current conditions of the road traffic safety system;

2. measuring the impact of various security activities;

3. comparison of different road traffic systems (e.g. countries, regions, etc.).

Therefore, Wegman and his team [35] proposed to 


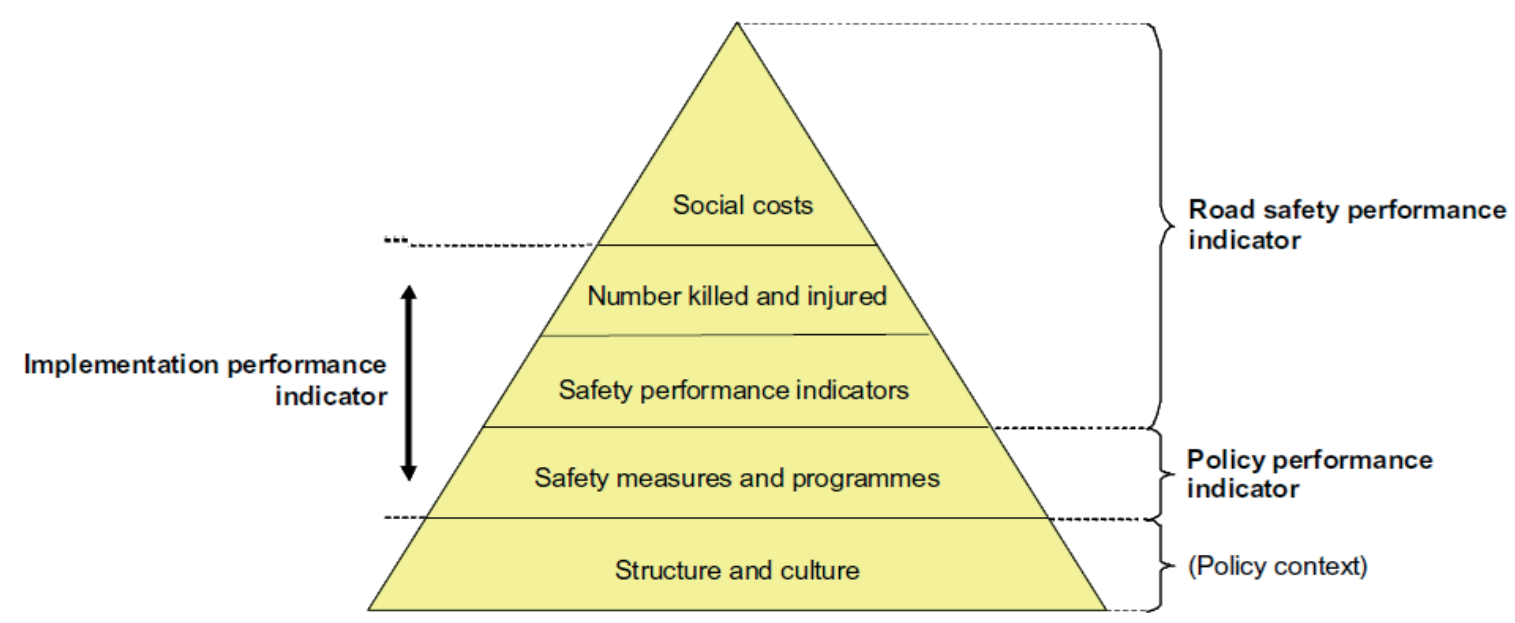

Figure 3 Three types of performance indicators and the SUNflower pyramid, [31]

distinguish three types of indicators in the sunflower pyramid and thus try to condense a huge amount of information - so he developed a comprehensive set of indicators - Composite Performance Safety Index - to measure road safety results in a given country. The first indicator - indicator of efficiency (effectiveness) of the road traffic safety - also called the result indicator - is based on the number of fatalities and injured road users; also takes into account indirect results (SPI) and social costs. It reflects the quality of the road traffic safety in the country. The second type of indicators indicates the quality of the road traffic safety policy implementation - it is an indicator of policy implementation efficiency. It combines its individual layers in the pyramid: "security measures and programs", performance indicators and the number of fatalities and injured. This indicator also includes elements of the lowest layer of "structure and culture". However, the third type of indicators indicates the quality of political documents for improving the road traffic safety (the so-called policy effectiveness indicator). It has two elements: the quality of conditions (strategies, programs, resources, coordination, institutional arrangements, etc.) and the quality of action plans and individual remedies for the road traffic safety. Thus, three types of indicators: efficiency indicator of the road traffic safety, policy implementation efficiency indicator and policy efficiency indicator can be integrated into the SUNflower pyramid (Figure 3). These three types of indicators are embedded in the political, economic, historical and geographical context, which are treated as a variable background [31].

Papadimitriou and Yannis [23] analysed the relationship between RTSMS and the road traffic safety at national level for 30 European countries based on the theoretical framework of the "SUNflower" pyramid. A composite index has been implemented for each of the five levels of the hierarchy. The results suggest that the RTSMS had no direct effect on the lethal outcome. However, it also turned out that such activities and tools as: a special budget for the road traffic safety, systematic assessment of the results of the road traffic safety programs and regular measurements of attitudes and behaviour of road users were positively linked to the operational level of the road traffic safety of the country based on performance indicators Safety Performance Indicators (SPIs), which are the third level in the SUNflower pyramid [21].

The theory of the road traffic safety indicators (SPI) was also dealt with by Hakkert and his team [39], who proposed SPI in seven main areas, such as alcohol and drug use; speed; protection systems; day lights; vehicles; roads and injury management. These areas were identified as key ones to achieve a significant improvement in the road traffic safety in EU countries. In turn, Hollo et al. [37], came to the conclusion that the SPIs do not allow full understanding of the road traffic safety trends, because - in addition to established and frequently used SPIs - there are many other explanatory variables for the national safety outcome, such as demography or technological development, etc. Therefore, they proposed that the analysis of the road traffic safety situation take into account various aspects of the complex socio-technical road traffic safety system, as well as organizational and structural factors.

In summary, it can be said that the SUNflower model describes the hierarchy of the road traffic safety goals from "structure and culture" to "social costs". This approach enables benchmarking of the road traffic safety and safety trends, as well as a quantitative representation of national security. It applies to security comparisons between all the countries in the European Union, as well as other countries around the world. It also creates a conceptual framework to identify factors that improve the road traffic safety.

\section{Results the ISO 39001 standard}

\subsection{The nature and scope of ISO 39001}

The ISO 39001 standard - Road Traffic Safety Management System is a standard introduced in 2012 [40]. It was developed with the support of experts from 40 countries and 16 liaison organizations, including the World Health Organization, the World Bank and the International Road Federation [41]. Its purpose is to encourage organizations 
Table 1 Number of certificates issued worldwide in the last three years - as of December 31, 2016, December 31, 2017 and December 31, 2018

\begin{tabular}{cccc}
\hline management system (MS) & $\begin{array}{c}\text { number of certificates issued } \\
\text { until 31.12.2016 }\end{array}$ & $\begin{array}{c}\text { number of certificates issued } \\
\text { until 31.12.2017 }\end{array}$ & $\begin{array}{c}\text { number of certificates issued } \\
\text { until 31.12.2018 }\end{array}$ \\
\hline ISO 39001:2012 & 478 & 620 & 547 \\
all MS & $1,644,357$ & $1,556,758$ & $1,307,622$ \\
\hline
\end{tabular}

Based on data obtained from The ISO Survey of Certifications-2018 [43].

to actively promote the road traffic safety, including by reducing the risk of injury resulting from the road traffic accidents. This standard is based on a process approach in quality management, including the Plan-Do-Check-Act cycle and the requirement for continuous improvement.

The ISO 39001 standard specifies the minimum requirements for the Road Traffic Safety Management System and establishes a set of best practices for the road traffic safety management, mainly by improving consistency within the organization. This is due to the very definition of the road traffic safety management system that should meet several "good practices" criteria, covering the entire policy development cycle, from program development to policy formulation, implementation and evaluation [23]. This system therefore provides instructions that serve as a basis for designing one's own tailored backbone of the road traffic safety activities by enabling one to transfer all the relevant processes and their control to one management system.

The ISO 39001 standard sets out harmonized requirements, based on international knowledge, to support public or private sector organizations that are involved in the regulation, design and operation of the road transport and interact with the road traffic safety system through: transport of goods and people; operation of devices generating transport demand; employees participating in the road transport system; road design, construction, operation and maintenance; design and production of passenger cars, trucks and other road vehicles and provision of medical assistance to emergency victims [25]. Therefore, the standard is a practical tool, among others for governments, vehicle fleet operators and all the organizations around the world who want to reduce the risk of death or serious injury from the road traffic accidents. In addition, for organizations involved in activities related to the road traffic safety, including by testing the effectiveness of the road traffic safety programs, analysing "black spots", or providing funding or awarding road traffic safety. It includes organizations of various sizes, locations and operating ranges. In addition to establishing a set of best practices for managing road traffic safety in organizations, it also sets out stakeholder requirements, such as legal requirements related to the role of organizations in the road system. Those requirements enable systematic identification and assessment of the degree of compliance with applicable legal requirements in the field of road traffic safety enforcement.

The ISO 39001 standard is a standard that aims to encourage organizations to actively contribute to the road traffic safety. By adopting the best practice management framework set out in ISO 39001, companies and enterprises can actively contribute to reducing the risk of death and serious injury due to the road traffic in their area of influence [42]. Hence, the implementation of the RTSMS in accordance with the ISO 39001 standard in the organization allows, above all, to reduce and sometimes eliminate the risk of death and serious injury resulting from the road traffic accidents. The standard also defines hazards and possibilities in the field of the road traffic safety, so that actions to improve processes and assess their effectiveness can be determined. In addition, it identifies and manages organizational processes that interact with the road traffic system and affect the road traffic safety. By adopting the structured holistic approach set out in PN-ISO 39001, organizations should be able to improve the road traffic safety performance in accordance with the law, while contributing to a broader goal for society through fewer road traffic accidents and fatalities.

For several years, the International Organization for Standardization (ISO) annually conducts a review of certificates for management system standards, which enables the certification market to be globally analysed. This is an excellent indicator, which, apart from e development of certification of individual management systems, also illustrates the indicator of development of the world economy. According to data presented in the last edition of the ISO survey (The ISO Survey of Certifications), which appeared in 2018 [43], by the end of December 2018 1,307,622 certificates were issued worldwide in relation to all the applicable management systems and 547 certificates for compliance with ISO 39001. Table 1 presents the number of certificates issued worldwide in the last three years as of December 31, 2016, December 31, 2017 and December 31, 2018. Although the ISO 39001 standard has been in force since 2012, the ISO Survey data on the number of certificates issued for compliance with this standard began to appear only from 2016 .

As it results from the data summarized in Table 1, for all the management systems whose analysis was included in the ISO Survey, a downward trend can be observed if at the end of 2016 there were more than 1.64 million certificates in the world, then a year later there were just over 1.55 million (decrease by 5.33\%) and at the end of 2017 - only 1.3 million (decrease by as much as $16 \%$ ). It is therefore not surprising that the number of certificates issued in 2018 for compliance with the ISO 39001 standard (RTSMS) is reduced - a decrease of $11.8 \%$, although in 2017 the number of these certificates increased by almost 
Table 2 Countries with the largest number of certificates issued regarding compliance with the requirements of ISO 39001 as of 31.12 .2018

\begin{tabular}{|c|l|c|}
\hline no. $\quad$ country & number of certificates issued (ISO 39001) \\
\hline 1. & Italy & 218 \\
\hline 2. & Spain & 79 \\
\hline 3. & Greece & 43 \\
\hline 4. & Japan & 39 \\
\hline 5. & Argentina & 28 \\
\hline 6. & Norway & 14 \\
\hline 7. & Thailand & 14 \\
\hline 8. & United Kingdom of Great Britain and Northern Ireland & 12 \\
\hline 9. & Peru & 11 \\
\hline 10. & Malaysia & 10 \\
\hline
\end{tabular}

Based on data obtained from The ISO Survey of Certifications-2018 [43].

$30 \%$. Since - as already mentioned - data on the number of certificates issued for compliance with the ISO 39001 standard began to appear in the ISO Survey only since 2016, so for now reliable conclusions cannot be drawn regarding the trend in the number of certificates issued in the world for compliance with this standard. Table 2 presents the ranking of ten countries that in 2018 recorded the largest number of certificates issued for compliance with the ISO 39001: 2012 standard.

Based on the data contained in Table 2, it can be concluded that the majority of certificates for compliance with ISO 39001: 2012 were issued in Italy, Spain, Greece and Japan. Noteworthy are also countries such as Thailand, Peru and Malaysia, which, although they do not belong to highly developed countries, with appropriate infrastructure, sufficient legal assumptions and systems and tools in the field of the road traffic safety, they have a relatively large - in relation to other countries, especially highly developed European economies - the number of certificates issued for compliance with the ISO 39001 standard.

\section{Discussions}

The current development of the geopolitical situation also has a significant impact on international transport and important transport connections; therefore the diversification of these threats is a logical factor ensuring efficient delivery of goods and thus the development of international trade [44]. The task of the transport sector is to meet the market requirements in terms of quality, flexibility, speed and safety of people and goods transport [45]. For the safety of transport systems, diagnostics of these systems and transport infrastructure facilities is important, as well. To compare the level of the road traffic safety in many countries, many indicators are used, including the most popular demographic indicators. Due to certain differences in transport systems, the automotive index and the industrialization of countries, the presented data cannot always be reflected equally. This causes some restrictions in assessing the state of safety, for these reasons systems were sought that would facilitate interpretation of data for individual countries. The road traffic safety management systems are more comprehensive solutions.

In general, the SUNflower model seeks to establish a causal relationship between the road traffic safety plans and programs with their results in terms of changes in the number of fatalities and injured and related costs [33]. The introduction of an intermediate level SPI and consequently, monitoring of progress through the SPI provides a much better understanding than monitoring only result indicators [36]. The popularity of this method in Europe is demonstrated by numerous studies presented in the literature [21, 23, 32, 35-37, 39].

In turn, the Road Traffic Safety Management System ISO 39001 is an important standard for identifying and managing risks related to the road traffic safety and road traffic for enterprises. It contains requirements and guidelines that allow companies implementing it to increase consistency, both within the company itself and between companies, as well as to create their own road traffic safety framework, which on the one hand reduces the complexity of this problem and on the other - allows including all the processes and control tools in one management system. In addition, the Road Traffic Safety Management System helps companies meet legal, industry and stakeholder requirements and - above all - reduce their negative impact on the environment and local communities.

\section{Conclusions}

The purpose of this article was to present the possibility of safety assessment in the field of the road traffic safety management systems based on two concepts: the SUNflower model and the ISO 39001 standard. The SUNflower pyramid with its various levels / layers turns out to be an excellent platform for managing the road traffic safety and the associated data collection system. As 
a result of the conducted analyses, however, a downward trend was noted as to the number of certificates issued for compliance with the ISO 39001 standard in the world. This may result from the fact that, first of all, it may indicate the emergence of more adequate management systems, or other tools or concepts to improve the road traffic safety; secondly, indicate inadequate public education and low levels of awareness in this area of stakeholders, including politicians, scientists, manufacturers, drivers (professional and non-professional), as well as other road users, including the vulnerable ones.
A positive sign of commitment to improving the road traffic safety is that, over the last decade, the demographic indicator: number of killed/100,000 residents in EU countries has decreased in almost all the member countries and has even decreased by half in some.

Therefore, given the growing number of vehicles on the road and the amount of transported goods and thus the occurring risks in the form of the road traffic accidents and congestion, issues of the road traffic safety management not only in the European Union are still a challenge and will have to be discussed in more detail.

\section{References}

[1] TURSKA, S., CHINORACKY, R., MADLENAKOVA, L., COREJOVA, T. Optimization of the delivery process in the urban area. In: 23rd International Conference. Transport Means 2019: proceedings. Part 2. 2018. p. 809-813.

[2] VETERNIK, M., GOGOLA, M. Examining of correlation between demographic development of population and their travel behaviour. Procedia Engineering [online]. 2017, 192, p. 929-934. ISSN 1877-7058. Available from: https://doi. org/10.1016/j.proeng.2017.06.160

[3] MAKKA, K., STACHOVA, D., KAMPOVA, K. Assessment of the mobile risk source in road transport. Communications Scientific Letters of the University of Zilina [online]. 2019, 21(1), p. 68-73. ISSN 1335-4205, eISSN 2585-7878. Available from: https://doi.org/10.26552/com.C.2019.1.68-73

[4] GASIOROWSKA-DENIS, E. The journey to safer roads [online]. 2013. Available from: www.iso.org

[5] World Health Organization. Global status report on road safety - time for action. Geneva: WHO, 2009.

[6] World Health Organization. Global status report on road safety. Geneva: WHO, 2018.

[7] METHORST, R., EENINK, R., CARDOSO, J., MACHATA, K., MALASEK, J. Single unprotected road user crashes: Europe we have a problem! Transportation Research Procedia [online]. 2016, 14, p. 2297-2305. ISSN 2352-1465. Available from: https://doi.org/10.1016/j.trpro.2016.05.246

[8] YANNIS G., PAPADIMITRIOU E., FOLLA K., NIKOLIC N., MOLNAR E. Developing a global road safety model. In: 97th Annual Meeting of the Transportation Research Board TRB: proceedings. 2018. 18-05057.

[9] BLISS, T., BREEN, J. Meeting the management challenges of the decade of action for road safety. IATSS Research [online]. 2012, 35(2), p. 48-55. ISSN 0386-1112. Available from: https://doi.org/10.1016/j.iatssr.2011.12.001

[10] The state of road safety and the activities carried out in this field in 2017 /Stan bezpieczenstwa ruchu drogowego oraz dzialania realizowane w tym zakresie w 2017 r (in Polish). Report of the National Road Safety Council / Raport Krajowej Rady Bezpieczenstwa Ruchu Drogowego, 2017.

[11] SHAN, Y., HERMANS, E., BAO, Q., BRIJS, T. WETS, G.: Road safety development in Europe: a decade of change (2001-2010). Accident Analysis and Prevention [online]. 2013, 60, p. 85-94. ISSN 0001-4575. Available from: https://doi.org/10.1016/j.aap.2013.08.013

[12] Road accidents in Poland in 2018. Warsaw: Polish Police Headquarters, 2019.

[13] KUCMIN, T., KUCMIN, A., TURSKA, D., TURSKI, A., NOGALSKI, A. Coping styles and dispositional optimism as predictors of post-traumatic stress disorder (PTSD) symptoms intensity in paramedics. Psychiatria Polska [online]. 2018, 52(3), p. 557-571. ISSN 0033-2674, eISSN 2391-5854. Available from: https://doi.org/10.12740/PP/68514

[14] BAK-GAJDA, D., BAK, J. Psychology of transport and road safety / Psychologia transportu $i$ bezpieczenstwa ruchu drogowego (in Polish). Diffin, 2010. ISBN 9788376412139.

[15] HANZL, J. Analytical model assessing the effect of increased traffic flow intensities on the road administration, maintenance and lifetime. Open Engineering [online]. 2019, 9(1), p. 359-366. eISSN 2391-5439. Available from: https://doi.org/10.1515/eng-2019-0045

[16] DROZDZIEL, P., WRONA, R. Legal and utility problems of accidents on express roads and motorways. In: 11th International Science and Technical Conference Automotive Safety 2018: proceedings. 2018. ISBN 9781538645796.

[17] OECD. Towards zero: ambitious road safety targets and the safe system approach. Paris: Organisation for Economic Co-operation and Development, 2008.

[18] World Health Organization. Global status report on road safety - time for action. Geneva: WHO, 2009.

[19] JOHNSTON, I. Beyond "best practice" road safety thinking and systems management - a case for cultural change. Safety Science [online]. 2010, 48(9), p. 1175-1181. ISSN 0925-7535. Available from: https://doi.org/10.1016/j.ssci.2009.12.003

[20] POLIAK, M., MRNIKOVA, M., SIMURKOVA, P., MEDVID, P., POLIAKOVA., A., HERNANDEZ, S. Social law in road transport like tool safety road transport. In: 11th International Science and Technical Conference Automotive Safety 2018: proceedings. 2018. ISBN 9781538645796. 
[21] VARHELYI, A. Road safety management - the need for a systematic approach. The Open Transportation Journal [online]. 2016, 10, p. 137-155. ISSN 1874-4478, eISSN 2667-1212. Available from: https://doi.org/10.2174/1874447801610010137

[22] BLISS, T., BREEN, J. Implementing the recommendations of the world report on road traffic injury prevention. Country guidelines for the conduct of road safety. Capacity reviews and the related specification of lead agency reforms, investment strategies and safety projects. Washington, DC: World Bank Global Road Safety Facility, 2009.

[23] PAPADIMITRIOU, E., YANNIS, G. Is road safety management linked to road safety performance? Accident Analysis and Prevention [online]. 2013, 59, p. 593-603. ISSN 0001-4575. Available from: https://doi.org/10.1016/j.aap.2013.07.015

[24] OECD. Road safety: What's the vision? Paris: Organisation for Economic Co-operation and Development, 2002.

[25] CRACKEL, L. R., SMALL, M. ISO 39001: A new tool for safe systems. In: Australasian Road Safety Research Policing and Education Conference: proceedings. 2010.

[26] MUHLRAD, N., GITELMAN, V., BUTTLER, I. Road safety management investigation model and questionnaire. Deliverable 1.2 of the EC FP7 Project DaCoTA. 2011.

[27] WONG, S. C., SZE, N. N. Is the effect of quantified road safety targets sustainable? Safety Science [online]. 2010, 48(9), p. 1182-1188. ISSN 0925-7535. Available from: https://doi.org/10.1016/j.ssci.2009.12.020

[28] BROUGHTON, J., KNOWLES, J. Providing the numerical context for British casualty reduction targets. Safety Science [online]. 2010, 48(9), p. 1134-1141. ISSN 0925-7535. Available from: https://doi.org/10.1016/j.ssci.2010.01.008

[29] CHAPELON, J., LASSARRE, S.: Road safety in France: the hard path toward science based policy. Safety Science [online]. 2010, 48(9), p. 1151-1159. ISSN 0925-7535. Available from: https://doi.org/10.1016/j.ssci.2010.04.015

[30] SCHULZE, H., KOSSMANN, I. The role of safety research in road safety management. Safety Science [online]. 2010, 48(9), p. 1160-1166. ISSN 0925-7535. Available from: https://doi.org/10.1016/j.ssci.2009.12.009

[31] WEGMAN, F., OPPE, S.: Benchmarking road safety performances of countries. Safety Science [online]. 2010, 48(9), p. 1203-1211. ISSN 0925-7535. Available from: https://doi.org/10.1016/j.ssci.2010.02.003

[32] KOORNSTRA, M., LYNAM, D., NILSSON, G., NOORDZIJ, P., PETTERSSON, H. E., WEGMAN, F., WOUTERS, P. SUNflower. A comparative study of the development of road safety in Sweden, the United Kingdom and the Netherlands. Leidschendam, The Netherlands: SWOV Institute for Road Safety Research, 2002.

[33] WEGMAN, F., SCHERMERS, G., VAN SCHAGEN, I. Towards a national road safety strategy for South Africa. The inception report. Leidschendam, The Netherlands: SWOV Institute for Road Safety Research, 2013.

[34] WEGMAN, F., EKSLER, V., HAYES, S., LYNAM, D., MORSINK, P., OPPE, S. SUNflower+6. A comparative study of the development of road safety in the SUNflower+6 countries. Final report. Leidschendam, The Netherlands: SWOV Institute for Road Safety Research, 2005.

[35] WEGMAN, F., COMMANDEUR, J., DOVEH, E., EKSleR, V., GITElMAN, V., HAKKERT, S., LYNAM, D., OPPE, S. SUNflower next: towards a composite performance index. Leidschendam, The Netherlands: SWOV Institute for Road Safety Research, 2008.

[36] WEGMAN, F., BERG, H-Y., CAMERON, I., THOMPSON, C., SIEGRIST, S., WEIJERMARS, W. Evidence-based and data-driven road safety management. IATSS Research [online]. 2015, 39, p. 19-25. ISSN 0386-1112. Available from: https://doi.org/10.1016/j.iatssr.2015.04.001

[37] HOLLO, P., EKSLER, V., ZUKOWSKA, J. Road safety performance indicators and their explanatory value: a critical view based on the experience of Central European countries. Safety Science [online]. 2010, 48(9), p. 1142-1150. ISSN 09257535. Available from: https://doi.org/10.1016/j.ssci.2010.03.002

[38] ADRIAANSE, A. Environmental policy performance indicators. A study on the development of indicators for environmental policy in the Netherlands. Hague: Ministry of Housing, Physical Planning and the Environment, Sdu Publishers, 1993.

[39] HAKKERT, A. S., GITELMAN, V., VIS, M. A. Road safety performance indicators: theory. Deliverable D3.6 of the EU FP6 project SafetyNet. Loughborough University Institutional Repository, 2007.

[40] EN ISO 39001:2012. Road traffic safety (RTS) management systems - requirements with guidance for use. Geneva, International Organization for Standardization, 2012.

[41] FROST, R. ISO road safety standard could help save thousands of lives [online] 2012. Available from: www.iso.org

[42] BREEN, J., WALTON, S. ISO 39001: tackling occupational road risk. Safety Management [online]. 2013. Available from: https://www.bsigroup.com/Documents/iso-39001/resources/ISO-39001-Tackling-Occupational-Road-Risk-UK-EN.pdf

[43] ISO Survey of certifications to management system standards. 2018.

[44] DROZDZIEL, P., BUKOVA, B., BRUMERCIKOVA, E.: Prospects of international freight transport in the East-West direction. Transport Problems [online]. 2015, 10(4), p. 5-13. eISSN 2300-861X. Available from: https://doi.org/10.21307/ tp-2015-043

[45] PECYNA, A., KRZYSIAK, Z., CABAN, J., SAMOCIUK W., BRUMERCIKOVA, E., BUKOVA, B., BUCZAJ, A. Analysis of transport of chemical products in the European Union (in Polish). Przemysl Chemiczny [online]. 2019, 98(8), p. 1330-1334. ISSN 0033-2496, eISSN 2449-9951. Available from: https://doi.org/10.15199/62.2019.8.25 